\title{
Redox-Neutral 1,3-Diol Synthesis by Base-Promoted Diastereoselective Alcohol-Aldolization
}

\author{
Na Shao, Jean Rodriguez, and Adrien Quintard*
}

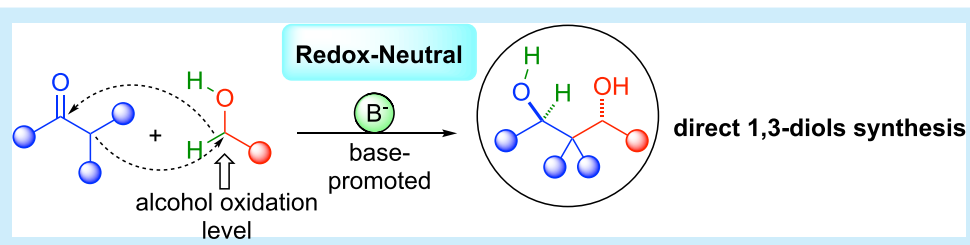

ABSTRACT: In order to prepare more efficiently key 1,3-diol fragments, we have devised a base-promoted redox-neutral condensation of ketones with alcohols. This diastereoselective alcohol-aldolization enables bypassing the classical oxidation and reduction steps necessary for the preparation of this crucial backbone by an overall redox-neutral formal borrowing hydrogen process. The starting alcohols constitute both the precursors of the in situ generated reactive aldehydes and the hydride source necessary for the chemoselective reduction of the aldol adduct intermediates.

T $\mathrm{n}$ order to minimize steps and waste generation associated with the stereoselective elaboration of complex organic scaffolds, the invention of redox-neutral approaches is crucial. ${ }^{1}$ These transformations, such as the popular borrowing hydrogen, have the power to avoid unnecessary operations and stoichiometric reagents associated with stepwise oxidation and reduction sequences, a step further toward eco-compatible synthesis. ${ }^{2}$ The elaboration of 1,3-diols, a common motif found in a wide variety of natural products and drugs (Scheme 1a), is a classic example of a synthetic sequence often involving successive undesired redox steps. ${ }^{3}$ This key architecture is usually constructed via aldol reaction between a carbonyl and an aldehyde (Scheme 1b). However, the starting aldehyde is often prepared by oxidation of the corresponding alcohol, and the aldol adduct must then be reduced to form the desired 1,3-diol. As a result, such a sequence implies two undesired time- and energy-consuming redox steps. In order to limit redox issues, different alternatives have been proposed such as the aldol Tishchenko-type disproportionation. However, this reaction occurs from the aldehyde oxidation level and requires an additional equivalent of aldehyde to promote the reduction of the aldol product through intramolecular hydride transfer. ${ }^{4}$ Most interestingly, a broad range of elegant metal-catalyzed redox-neutral couplings have been developed such as the allylations of alcohols. ${ }^{5}$ While these strategies elegantly enable constructing alcohols directly from the same oxidation state, further derivatizations of the obtained alkenes through redox manipulation is mandatory to obtain complex polyol scaffolds.

Given 1,3-diols oxidation state, in order to obtain the best synthetic efficiency, their elaboration should imply a redox-neutral cascade construction by aldol condensation directly between a ketone and an alcohol. Inspired by the synthetic economies provided by
Scheme 1. 1,3-Diol Synthetic Challenges and Proposed Alcohol-Aldolization

a) 1,3-diols significance:

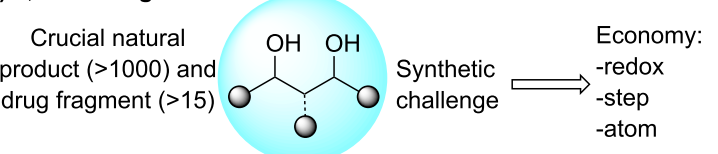

b) Classical 1,3-diol synthesis

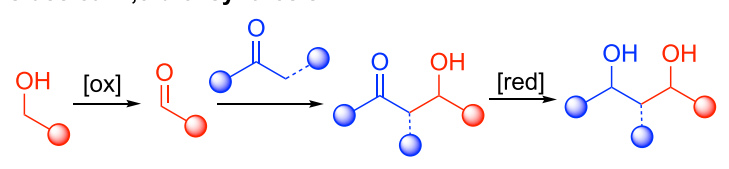

c) Alcohol-aldolization (this work):

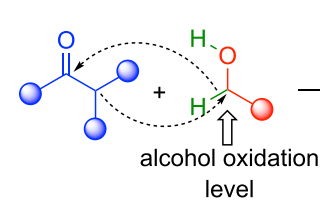

(B)

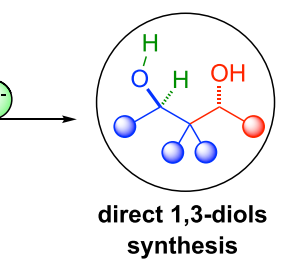

borrowing hydrogen approaches, we present a new conceptual alcohol-aldolization for the direct construction of anti-1,3-diols 
involving a base-promoted overall redox-neutral process starting from simple primary alcohols and functionalized ketones (Scheme 1c).

Key features for the design of a successful alcoholaldolization are the efficient reduction of the carbonyl compound and its enolizable character, ensuring both the aldolization step and a chemoselective final hydrogen transfer. To meet these requirements, we initially selected $\alpha$-difluorinated acetophenone $\mathbf{1} \mathbf{a}^{6,7}$ and benzyl alcohol (2a) as model substrates (Table 1). ${ }^{8,9}$ Besides representing a proof of concept for the

Table 1. Selected Optimization for the Alcohol-Aldolization

\begin{tabular}{|c|c|c|c|c|}
\hline entry $^{a}$ & conditions & $\begin{array}{l}3 \mathrm{a} / 4 \\
\text { ratio }^{b}\end{array}$ & $3 \mathbf{a} \mathrm{dr}^{b}$ & $\begin{array}{l}\text { 3a yield } \\
(\%)(\mathrm{dr} \\
\text { isolated })^{c}\end{array}$ \\
\hline 1 & $\mathrm{KOH}$ (2 equiv), $t-\mathrm{BuOH}, 60^{\circ} \mathrm{C}$ & $1: 1.4^{d}$ & $7: 1$ & nd \\
\hline 2 & $\mathrm{KOH}$ (2 equiv), toluene, $60^{\circ} \mathrm{C}$ & $1.9: 1$ & $10: 1$ & nd \\
\hline 3 & $\begin{array}{l}\text { KOH (2 equiv),TBACl } \\
\left(20 \text { mol \%), toluene, } 60^{\circ} \mathrm{C}\right.\end{array}$ & $2.7: 1$ & $8: 1$ & nd \\
\hline 4 & $\begin{array}{l}\mathrm{KOH}(0.5 \text { equiv }), \mathrm{TBACl} \\
(20 \mathrm{~mol} \%), 60^{\circ} \mathrm{C}\end{array}$ & 1:1.7 & $4: 1$ & nd \\
\hline 5 & $\begin{array}{l}\mathrm{KOH}(10 \text { equiv),TBACl } \\
(20 \mathrm{~mol} \%) \text {, toluene, } 60^{\circ} \mathrm{C}\end{array}$ & $1: 4.2$ & nd & nd \\
\hline 6 & $\begin{array}{l}\text { KOH (2 equiv),TBACl } \\
(20 \mathrm{~mol} \%),), \text { PhCOPh } \\
(20 \mathrm{~mol} \%) \text {, toluene, } 40^{\circ} \mathrm{C}\end{array}$ & $3.5: 1$ & $8: 1$ & $61(99: 1)$ \\
\hline 7 & $\begin{array}{l}\text { KOH (2 equiv), TBAI } \\
(20 \mathrm{~mol} \%), \text { PhCOPh } \\
(20 \mathrm{~mol} \%) \text {, toluene, } 40{ }^{\circ} \mathrm{C}\end{array}$ & 4.2:1 & 8:1 & 68(99:1) \\
\hline 8 & $\begin{array}{l}\mathrm{Al}(\mathrm{Oi}-\mathrm{Pr})_{3}(50 \mathrm{~mol} \%) \text {, toluene } \\
\text { or THF, } 60^{\circ} \mathrm{C}\end{array}$ & $1: 99$ & nd & nd \\
\hline
\end{tabular}

${ }^{a}$ Reactions performed using $0.1 \mathrm{mmol}$ of $1 \mathrm{a}$ and $0.3 \mathrm{mmol}$ of $\mathbf{2 a}$ during $18-24 \mathrm{~h} .{ }^{b}$ Determined by ${ }^{1} \mathrm{H}$ and ${ }^{19} \mathrm{~F}$ NMR. ${ }^{c}$ Isolated yield after purification by recrystallization. ${ }^{d}$ Formation of approximately 1 equiv of benzoic acid with respect to 3 a.

alcohol-aldolization, such a condensation would provide valuable fluorinated 1,3-diols possessing a key difluoromethylene unit of great biological interest. ${ }^{10}$

Our initial experiments involved application of an iron complex to initiate the reversible hydrogen transfer; ${ }^{11}$ however, control experiments revealed that the redox process was mostly promoted by the base presumably through MeerweinPonndorf-Verley-type hydride transfers (vide infra). ${ }^{12}$ As a result, we focused our attention on the identification of appropriate basic conditions for this reaction (Table 1).

In $t$ - $\mathrm{BuOH}$ as protic solvent, using different bases (see the SI for details), such as a 2 -fold excess of $\mathrm{KOH}$ at $60{ }^{\circ} \mathrm{C}$ (entry 1 ), anti-1,3-diol 3a was formed diastereoselectively (7:1 dr) together with secondary alcohol 4 in a 1:1.4 ratio indicating a large amount of undesired reduction of the starting difluoro ketone 1a (entry 1). Moreover, under these conditions, a large amount of benzoic acid was also observed, suggesting either competing aerobic oxidation mechanism or a release from a Tishchenko-type disproportionation. These preliminary observations revealed that to be efficient, the system should outcompete undesired 1a reduction as well as Tishchenko reduction all-consuming undesired amounts of $\mathbf{1 a}$ and $\mathbf{2 a}$. Turning to the use of toluene considerably improved the process forming $\mathbf{3 a}$ as the major product with only minor formation of benzoic acid, providing strong evidence for our proposed metalfree redox-neutral pathway (entry 2). In addition, the final reduction step occurred with good diastereocontrol, providing $3 \mathrm{a}$ in $10: 1 \mathrm{dr}$.

In order to accelerate the aldolization step and potentially limit the competing reduction of $1 \mathrm{a}$, we added $20 \mathrm{~mol} \%$ of tetrabutylammonium chloride ( $\mathrm{TABCl})$, improving the selectivity to a 2.7:1 ratio between $3 \mathbf{a}$ and $\mathbf{4}$ (entry 3 ) ${ }^{13}$ In contrast, using a substoichiometric amount of $\mathrm{KOH}$ (0.5 equiv, entry 4) decreased the selectivity of the alcohol-aldolization, while with a large excess of $\mathrm{KOH}$ ( 10 equiv, entry 5 ) only a minor amount of the expected product was observed. In order to facilitate the reaction through the initial formation of a small amount of aldehyde (vide infra), $20 \mathrm{~mol} \%$ of benzophenone (PhCOPh) was added as sacrificial hydride acceptor. ${ }^{14}$ Performing the reaction at $40{ }^{\circ} \mathrm{C}$ resulted in a significantly improved selectivity in favor of 3a, isolated in $61 \%$ yield (99:1 dr, entry 6), while TBAI was found to be optimum forming $3 \mathrm{a}$ in $68 \%$ isolated yield (99:1 dr, entry 7). Finally, the role of the base is crucial for the reaction since use of $\mathrm{Al}(\mathrm{O} i-\mathrm{Pr})_{3}$, an excellent Lewis acid catalyst for the Meerwein-Ponndorf-Verley process, only rapidly reduced 1 a to 4 (entry 8 ).

With optimal conditions for the alcohol-aldolization in hand, we next confirmed the generality of this method on other substrates (Scheme 2). The reaction tolerated different starting $\alpha$-difluorinated acetophenones containing either electrondonating groups $\mathbf{1} \mathbf{b}, \mathbf{c}, \mathbf{h}, \mathbf{i}$ in the ortho-, meta-, or para-position or electron-withdrawing halogen atoms $\mathbf{1 d - f}$. All of the corresponding 1,3-diols 3 could be isolated in $27-81 \%$ yield and 4:1 to $13: 1 \mathrm{dr}$. However, the sharp drop in electron density with $p$-nitro acetophenone $2 \mathrm{~g}$ resulted in its fast reduction, and only a trace amount of $3 \mathrm{~g}$ was observed.

Interestingly, starting from monofluorinated ketone $\mathbf{1 j}$, anti1,3 -diol $3 \mathbf{j}$ could be isolated in unoptimized $23 \%$ yield, demonstrating the potential of this approach for other classes of substrates. Starting from $\alpha$-difluorinated acetophenone 1a, a broad range of different primary alcohols $\mathbf{2} \mathbf{b}-\mathbf{o}$ also reacted in the process. Starting from benzylic alcohols containing para- or ortho-electron-donating or electron-withdrawing substituents afforded diastereoselectively 1,3 -diols $\mathbf{3 b}-\mathbf{b}, \mathbf{h}, \mathbf{i}, \mathbf{k}$ in $45-72 \%$ yield and 5:1 to $>20: 1 \mathrm{dr}$. Other classes of substrates such as naphthalene, furan-, and thiophene-containing alcohols also reacted well, providing $31-\mathbf{n}$ in $38-56 \%$ yield albeit with lower diastereocontrol concerning the smaller rings (2:1 and 4:1 dr). Interestingly, cinnamyl alcohol also provided diol 3o opening access to other classes of compounds. In contrast, under those conditions, the use of ethanol only provided partial reduction to 4.

In order to shed light on the mechanism of this alcoholaldolization, several control experiments were performed. First, as mentioned during the optimization, the reaction of $1 \mathbf{a}$ with benzyl alcohol (2a) formed the desired product 3a together with only minor amounts of alcohol $\mathbf{4}$ and benzoic acid $\mathbf{5}$ as side products (Scheme 3a). This indicates that the evolution of the aldol intermediate by Tishchenko-type disproportionation with the in situ formed aldehyde producing benzoic acid 5 represents a minor pathway.

A Meerwein-Ponndorf-Verley-type hydride transfer under those conditions was further demonstrated by reducing ketone 1a to $\mathbf{4}$ with $29 \%$ conversion using 3 equiv of 2-propanol $\mathbf{6}$ as hydride donor (Scheme $3 b$ ). In addition to providing evidence for the proposed mechanism, this type of reactivity is also interesting for a potential eco-compatible reduction of 
Scheme 2. Scope of the Alcohol-Aldolization

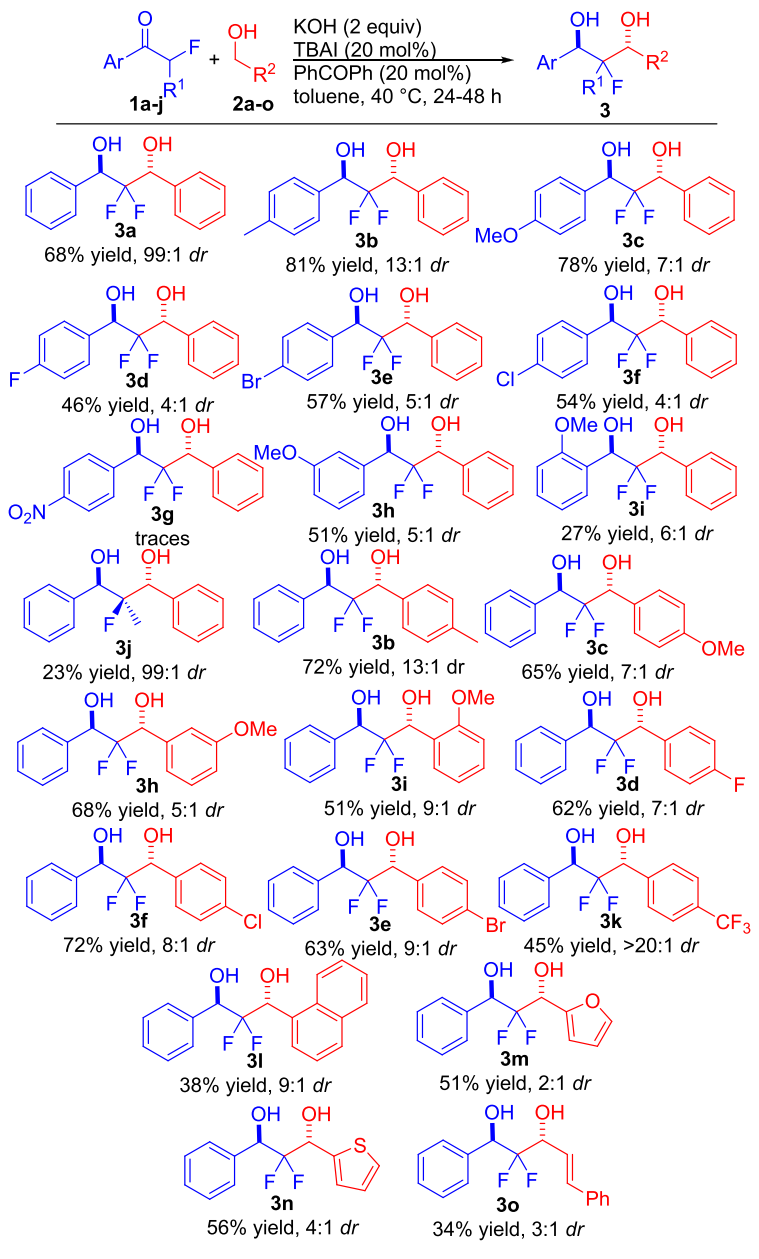

Scheme 3. Mechanistic Experiments

a)

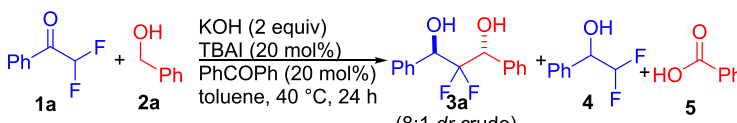

b)

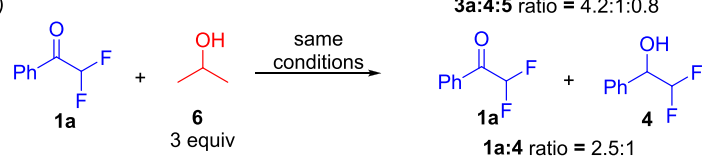

c)<smiles>[3H]C([PH2+])[PH2+]C(=O)C(F)(F)C(F)(F)C(O)c1ccccc1</smiles>

No reaction

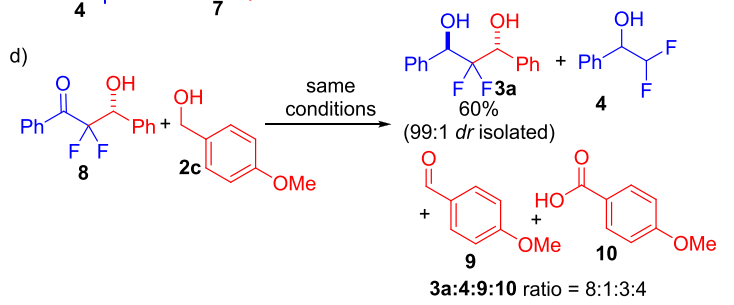

fluorinated ketones involving cheap and nonhazardous reagents. The reduction of $\alpha$-difluorinated acetophenones is also poorly reversible since when 4 was treated with ketone 7 no hydride transfer occurred (Scheme 3c). Similarly, a crossover experiment treating $\mathbf{3 a}$ under the same conditions with another benzylic alcohol confirmed the irreversibility of the final reduction (see the SI). Finally, alcohol 2c irreversibly reduces aldol product $\mathbf{8}$ to 1,3-diol 3a with good diastereocontrol together with the formation of a small amount of alcohol 4 (Scheme 3d). ${ }^{15}$ This clearly indicates that a retro-aldol reaction is partially competing with the direct reduction, which was further confirmed when $\mathbf{8}$ was treated under the same conditions without hydride donor (see the SI). Interestingly, in the reaction of Scheme 3d, carboxylic acid $\mathbf{1 0}$ is formed together with aldehyde 9. This suggests that the aldehyde able to accumulate in this equation is partially oxidized through aerobic oxidation and a competing Tishchenko reaction as confirmed through control experiments (see the SI).

Altogether, these observations suggest that the major pathway for this alcohol-aldolization follows the mechanism proposed in Scheme 4a. The redox steps involve a base-promoted

Scheme 4. Mechanism of the Alcohol-Aldolization

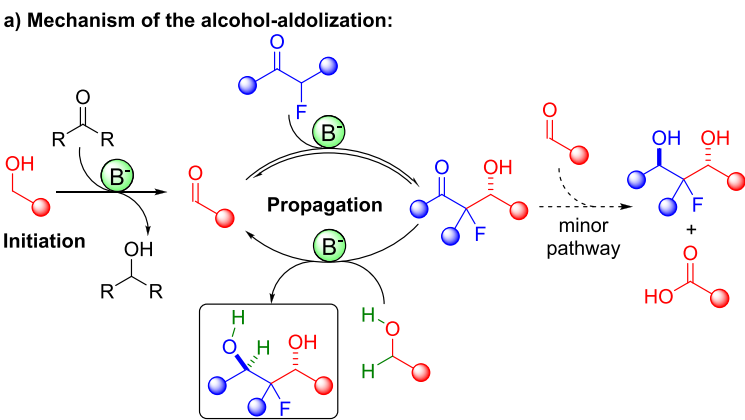

b) Meerwein-Ponndorf-Verley type hydride transfer:

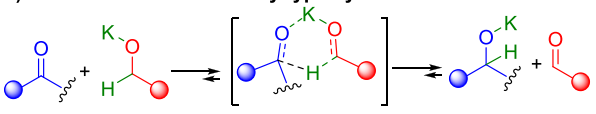

Meerwein-Ponndorf-Verley-type hydride transfer from alcoholates to carbonyls (Scheme $4 \mathrm{~b}$ ). From the primary alcohol, hydride transfer to a sacrificial acceptor (fluorinated ketone or benzophenone $)^{16}$ initiates the reaction by generating a small amount of reactive aldehyde. The propagation cycle occurs through a fast and reversible base-promoted ketone addition creating the aldol adduct intermediate. Its diastereoselective reduction by hydrogen transfer from another molecule of alcohol regenerates the aldehyde, thus closing the propagation cycle. The final reduction is strongly irreversible, shifting the equilibrium toward the desired 1,3-diol.

The diastereoselective reduction of the nonenolizable aldol intermediate can be rationalized by formation of a hydroxycarbonyl chelate as already observed in Meerwein-PonndorfVerley hydride transfers. ${ }^{9 a}$ In addition, this behavior also argues in favor of its chemoselective reduction in the presence of the starting ketone, whose reduction is hampered by enolization in basic media.

With these conditions, limitations can arise when the aldol adduct is reduced too slowly by the alcohol. Under such scenario, fast reduction of the starting ketone could result in aldehyde accumulation and subsequent parasitic aerobic 
oxidation or Tishchenko reduction, thus decreasing the yield (Scheme 4a). As a result, future development in this chemistry and extension to other class of substrates could rely on the use of multiple catalysts able to selectively promote each elementary step.

To conclude, we have developed a new condensation of fluorinated ketones with alcohols enabling the direct synthesis of 1,3-diols through a base-promoted redox-neutral process. This transformation occurs through several Meerwein-PonndorfVerley-type hydride transfers combined with an aldol condensation to the in situ generated aldehyde. By using the primary alcohol as hydride source, this alcohol-aldolization provides considerable synthetic economies (step, reagent, waste) and enables bypassing the classical oxidation and reduction steps necessary for the preparation of valuable 1,3-diol scaffolds. We are convinced that the concept described here will serve as a keystone for the development of other powerful redox-neutral condensations or related reactions using hydride transfer or borrowing hydrogen metal catalysts.

\section{AUTHOR INFORMATION}

Corresponding Author

Adrien Quintard - Aix Marseille Univ, CNRS, Centrale

Marseille, iSm2, Marseille 13397, France; ๑ orcid.org/0000-

0003-0193-6524; Email: adrien.quintard@univ-amu.fr

\section{Authors}

Na Shao - Aix Marseille Univ, CNRS, Centrale Marseille, iSm2, Marseille 13397, France

Jean Rodriguez - Aix Marseille Univ, CNRS, Centrale Marseille, iSm2, Marseille 13397, France

\section{Funding}

The Agence National de la Recherche (ANR-19-CE07-0033), the Centre National de la Recherche Scientifique (CNRS), and Aix-Marseille Université are warmly acknowledged for financial support. N.S. thanks the China Scholarship Council for a $\mathrm{PhD}$ grant (no. 201908070004).

Notes

The authors declare no competing financial interest.

\section{ACKNOWLEDGMENTS}

All technical staff from Aix-Marseille Spectropole are acknowledged for their support.

\section{REFERENCES}

(1) For concept of redox-economies in synthesis, see: (a) Burns, N. Z.; Baran, P. S.; Hoffmann, R. W. Angew. Chem., Int. Ed. 2009, 48, 28542867. (b) Newhouse, T.; Baran, P. S.; Hoffmann, R. W. Chem. Soc. Rev.
2009, 38, 3010-3021. For other synthetic-economies concepts, see: (c) Trost, B. M. Science 1991, 254, 1471-1477. (d) Wender, P. A.; Miller, B. L. Nature 2009, 460, 197-201. (e) Doerksen, R. S.; Meyer, C. C.; Krische, M. J. Angew. Chem., Int. Ed. 2019, 58, 14055-14064.

(2) For reviews on redox-neutral cascades, see: (a) Hamid, M. H. S. A.; Slatford, P. A.; Williams, J. M. J. Adv. Synth. Catal. 2007, 349, 15551575. (b) Nixon, T. D.; Whittlesey, M. K.; Williams, J. M. J. Dalton Trans. 2009, 753-762. (c) Watson, A. J. A.; Williams, J. M. J. Science 2010, 329, 635-636. (d) Dobereiner, G. E.; Crabtree, R. H. Chem. Rev. 2010, 110, 681-703. (e) Gunanathan, C.; Milstein, D. Science 2013, 341, 1229712-1229712. (f) Haibach, M. C.; Seidel, D. Angew. Chem., Int. Ed. 2014, 53, 5010-5036. (g) Quintard, A.; Rodriguez, J. Chem. Commun. 2016, 52, 10456-10473. (h) Huang, F.; Liu, Z.; Yu, Z. Angew. Chem., Int. Ed. 2016, 55, 862-875. (i) Bhawal, B. N.; Morandi, B. Angew. Chem., Int. Ed. 2019, 58, 10074-10103.

(3) (a) Staunton, J.; Weissman, K. J. Nat. Prod. Rep. 2001, 18, 380416. (b) Bode, S. E.; Wolberg, M.; Müller, M. Synthesis 2006, 557-588. (c) Schetter, B.; Mahrwald, R. Angew. Chem., Int. Ed. 2006, 45, 75067525. (d) Herkommer, D.; Schmalzbauer, B.; Menche, D. Nat. Prod. Rep. 2014, 31, 456-467. (e) Kumar, P.; Tripathi, D.; Sharma, B. M.; Dwivedi, N. Org. Biomol. Chem. 2017, 15, 733-761. (f) Sperandio, C.; Rodriguez, J.; Quintard, A. Org. Biomol. Chem. 2020, 18, 1025-1035.

(4) (a) Kulpinski, M. S.; Nord, F. F. J. J. Org. Chem. 1943, 08, 256270. (b) Mahrwald, R. Curr. Org. Chem. 2003, 7, 1713-1723. (c) Mlynarski, J. Eur. J. Org. Chem. 2006, 2006, 4779-4786. (d) Schneider, C.; Boomhoff, M. Aldol Reactions in Domino Processes. Domino Reactions, in Domino Reactions: Concepts for Efficient Organic Synthesis; Wiley VCH, 2013.

(5) (a) Kim, I. S.; Ngai, M.-Y.; Krische, M. J. J. Am. Chem. Soc. 2008, 130, 6340-6341. (b) Lu, Y.; Kim, I. S.; Hassan, A.; Del Valle, D. J.; Krische, M. J. Angew. Chem., Int. Ed. 2009, 48, 5018-5021. (c) Gao, X.; Han, H.; Krische, M. J. J. J. Am. Chem. Soc. 2011, 133, 12795-12800.

(d) Ketcham, J. M.; Shin, I.; Montgomery, T. P.; Krische, M. J. Angew. Chem., Int. Ed. 2014, 53, 9142-9150. (e) Feng, J.; Kasun, Z. A.; Krische, M. J. J. Am. Chem. Soc. 2016, 138, 5467-5478.

(6) For recent reviews on bis-fluorinated ketones: (a) Pattison, G. Eur. J. Org. Chem. 2018, 2018, 3520-3540. (b) Sadhukhan, S.; Santhi, J.; Baire, B. Chem. - Eur. J. 2020, 26, 7145-7175.

(7) (a) McBee, E. T.; Roberts, C. W.; Curtis, S. G. J. Am. Chem. Soc. 1955, 77, 6387-6390. (b) McGrath, T. F.; Levine, R. J. J. Am. Chem. Soc. 1955, 77, 3656-3658. (c) Naji, N.; Moreau, P. J. Fluorine Chem. 1988, 38, 19-40. (d) Sasaki, S.; Yamauchi, T.; Kubo, H.; Kanai, M.; Ishii, A.; Higashiyama, K. Tetrahedron Lett. 2005, 46, 1497-1500. (e) Sokeirik, Y. S.; Sato, K.; Omote, M.; Ando, A.; Kumadaki, I. J. Fluorine Chem. 2006, 127, 150-152. (f) Mikami, K.; Murase, T.; Itoh, Y. J. Am. Chem. Soc. 2007, 129, 11686-11687.

(8) For the use of fluorinated ketones in aldol-Tishchenko reactions, see: (a) Xu, W.; Médebielle, M.; Bellance, M.-H.; Dolbier, W. R. Adv. Synth. Catal. 2010, 352, 2787-2790. (b) Asano, T.; Kotani, S.; Nakajima, M. Org. Lett. 2019, 21, 4192-4196.

(9) For other examples of preparation of bis-fluorinated 1,3-diols, see: (a) Kuroboshi, M.; Ishihara, T. Bull. Chem. Soc. Jpn. 1990, 63, 11851190. (b) Prakash, G. K.S.; Hu, J.; Mathew, T.; Olah, G. A. Angew. Chem., Int. Ed. 2003, 42, 5216-2019. (c) Clarke, M. L.; France, M. B.; Knight, F. R.; Frew, J. J. R.; Roff, G. J. Synlett 2007, 2007 (11), 17391741. (d) Han, C.; Hoo Kim, E.; Colby, D. A. J. J. Am. Chem. Soc. 2011, 133, 5802-5805. (e) Zhang, P.; Wolf, C. Angew. Chem., Int. Ed. 2013, 52, 7869-7873. (f) Yu, J.-S.; Liu, Y.-L.; Tang, J.; Wang, X.; Zhou, J. Angew. Chem., Int. Ed. 2014, 53, 9512-9516. (g) Doi, R.; Ohashi, M.; Ogoshi, S. Angew. Chem., Int. Ed. 2016, 55, 341-344.

(10) (a) Muller, K.; Faeh, C.; Diederich, F. Science 2007, 317, 18811886. (b) Purser, S.; Moore, P. R.; Swallow, S.; Gouverneur, V. Chem. Soc. Rev. 2008, 37, 320-330. (c) O'Hagan, D. Chem. Soc. Rev. 2008, 37, 308-319. (d) Wang, J.; Sánchez-Roselló, M.; Aceña, J. L.; del Pozo, C.; Sorochinsky, A. E.; Fustero, S.; Soloshonok, V. A.; Liu, H. Chem. Rev. 2014, 114, 2432-2506. (e) O’Hagan, D.; Wang, Y.; Skibins, M.; Slawin, A. M. Z. Pure Appl. Chem. 2012, 84, 1587-1595. For fluorinated polyols interest, see: (f) Sperandio, C.; Quintard, G.; 
Naubron, J.-V.; Giorgi, M.; Yemloul, M.; Parrain, J.-L.; Rodriguez, J.; Quintard, A. Chem. - Eur. J. 2019, 25, 15098-15105.

(11) (a) Quintard, A.; Constantieux, T.; Rodriguez, J. Angew. Chem., Int. Ed. 2013, 52, 12883-12887. (b) Irrgang, T.; Kempe, R. Chem. Rev. 2019, 119, 2524-2549.

(12) For examples of base promoted hydride-transfer reactions, see: (a) Ekström, J.; Wettergren, J.; Adolfsson, H. Adv. Synth. Catal. 2007, 349, 1609-1613. (b) Zhang, W.; Liu, M.; Wu, H.; Ding, J.; Cheng, J. Tetrahedron Lett. 2008, 49, 5336-5338. (c) Polshettiwar, V.; Varma, R. S. Green Chem. 2009, 11, 1313-1316. (d) Sedelmeier, J.; Ley, S. V.; Baxendale, I. R. Green Chem. 2009, 11, 683-685. (e) Allen, L. J.; Crabtree, R. H. Green Chem. 2010, 12, 1362-1364. (f) Xu, J.; Zhuang, R.; Bao, L.; Tan, G.; Zhao, Y. Green Chem. 2012, 14, 2384-2387. (g) Xu, Q.; Chen, J.; Liu, Q. Adv. Synth. Catal. 2013, 355, 697-704. (h) Liang, Y.-F.; Zhou, X.-F.; Tang, S.-Y.; Huang, Y.-B.; Feng, Y.-S.; Xu, H.-J. RSC Adv. 2013, 3, 7739-7742. (i) Xu, Q.; Li, Q.; Zhu, X.; Chen, J. Adv. Synth. Catal. 2013, 355, 73-80. (j) Xu, Q.; Chen, J.; Tian, H.; Yuan, X.; Li, S.; Zhou, C.; Liu, J. Angew. Chem., Int. Ed. 2014, 53, 225229. (k) Ballester, J.; Caminade, A.-M.; Majoral, J.-P.; Taillefer, M.; Ouali, A. Catal. Commun. 2014, 47, 58-62. (1) Wang, D.; Deraedt, C.; Ruiz, J.; Astruc, D. J. Mol. Catal. A: Chem. 2015, 400, 14-21. (m) Yang, H.; Cui, X.; Dai, X.; Deng, Y.; Shi, F. Nat. Commun. 2015, 6, 64786488. (n) Li, Q.-Q.; Xiao, Z.-F.; Yao, C.-Z.; Zheng, H.-X.; Kang, Y.-B. Org. Lett. 2015, 17, 5328-5331. (o) Xiao, M.; Yue, X.; Xu, R.; Tang, W.; Xue, D.; Li, C.; Lei, M.; Xiao, J.; Wang, C. Angew. Chem., Int. Ed. 2019, 58, 10528-10536.

(13) For general aspects on ammonium salt catalysis, see: (a) Quaternary Ammonium Salts, Their Use in Phase-Transfer Catalyzed Reactions; Jones, R. A., Ed.; Academic Press: New York. 2001. (b) Asymmetric Phase-Transfer Catalysis; Maruoka, K. J., Ed.; WileyVCH: Weinheim, 2008. (c) Qian, D.; Sun, J. Chem. - Eur. J. 2019, 25, 3740 .

(14) For addition of ketone as a catalytic promoter, see ref $12 \mathrm{~g}, \mathrm{i}, \mathrm{m}, \mathrm{o}$ and: (a) Han, X.; Wu, J. Angew. Chem., Int. Ed. 2013, 52, 4637-4640. (b) Ng, T. W.; Liao, G.; Lau, K. K.; Pan, H.-J.; Zhao, Y. Angew. Chem., Int. Ed. 2020, 59, 11384-11389. For the use of benzophenone in transfer hydrogenation, see ref $12 \mathrm{k}$.

(15) Reduction of $\mathbf{8}$ is also possible using 3 equiv of 2-propanol but leads to more retro-aldol and Tishchenko side reduction. See the Supporting Information for details.

(16) Given the same type of reactivity observed in the absence of benzophenone resulting only in slightly decreased yield, we can rule out a possible radical pathway. Benzophenone is believed to act as a hydride acceptor facilitating the initiation step without consuming too much starting ketone. The lower yield obtained in the redox-neutral aldolization when performing the reaction under air indicates that oxidation by oxygen is less likely to initiate the process. This is confirmed by the absence of peroxide formation at the end of these alcohol aldolizations. 